Management options

\title{
Localised carcinoma of the prostate: a paradigm of uncertainty
}

\author{
Sarbjinder S Sandhu, Amir V Kaisary
}

\begin{abstract}
Summary
The incidence and prevalence of prostate cancer is increasing. A number of aetiological factors including age, race, family history and diet have been implicated. The majority of patients present with disease which is amenable only to palliation. Digital rectal examination, serum prostate-specific antigen and transrectal ultrasound can lead to a prostatic biopsy. Transrectal ultrasound, magnetic resonance imaging, bone scan and a chest $X$-ray are used for staging. The management of localised cancer is shrouded in uncertainty. Three options exist, watchful waiting, radiotherapy, and radical total prostatectomy. The published data are inadequate for a valid comparison of these, and none has been shown to offer an advantage. Surgery, and to a lesser degree radiotherapy, have a significant morbidity. It is hoped that through better understanding our management of this disease will improve.
\end{abstract}

Keywords: prostate cancer

Department of Urology,

The Royal Free Hospital School of

Medicine, Pond Street, London NW3

2QG, UK

SS Sandhu

AV Kaisary

Accepted 18 November 1996
In 1993, 9530 deaths occurred due to carcinoma of the prostate - the second commonest cancer-related cause of death. Data from the Office of Population Censuses and Surveys (OPCS) has recorded an increase in the incidence from 34.0 per 100000 in 1980 to 50.7 per 100000 in 1989 . The OPCS believe that the increase in the incidence is not only due to better detection but also that the underlying prevalence of the prostatic carcinoma is increasing. An ageing population coupled with an increased awareness amongst the medical profession and the lay public are also contributory factors. However, an obvious disparity exists between the number of patients with carcinoma of the prostate and the number that succumb to the disease.

\section{Aetiology}

A number of risk factors have been implicated, age is the most important, $95 \%$ of cases occur between 45 and 89 years, the median age of presentation being $72 ; 90 \%$ of deaths occur after 65 at a median age of 77 years. Post-mortem studies have revealed $40 \%$ of 90 -year-old patients have carcinoma of the prostate. Race is a risk factor, blacks are affected more than whites and orientals have the lowest prevalence. The highest prevalence is amongst black men in Washington DC. An individual's risk is increased three-fold if a first-degree relative has carcinoma of the prostate. Genealogy studies are being undertaken by the group from Johns Hopkins with the large Mormon population in Utah and familial prostate cancer is being studied by a group at the Royal Marsden. A high-fat diet has been implicated, as have androgens. Androgens are essential for gland proliferation and, in experimental models, induce carcinoma of the prostate. There is no clear relationship between serum testosterone levels and prostatic carcinoma but patients with low levels have a poor response to treatment.

\section{Presentation}

Carcinoma of the prostate presents principally in four ways. Patients present with symptoms of bladder outlet obstruction (the majority), an incidental finding upon histopathological examination of prostatic chips, metastatic disease, or through screening, whether specifically for carcinoma of the prostate or during a routine examination. Among men with newly diagnosed carcinoma of the prostate, one-third have distant metastasis, $10-15 \%$ have locally extensive tumour (about half have lymph node metastasis), and 50-60\% have clinically localised disease (a third have lymph node metastasis). Thus, twothirds of newly diagnosed patients have disease which is not localised and so is amenable only to palliation. ${ }^{1}$

\section{Diagnosis}

Three primary diagnostic tests exist to initiate histological or cytological tissue sampling: digital rectal examination, transrectal ultrasound, and prostate specific antigen (PSA). The clinical impression of the examining urologist

\begin{tabular}{|l|}
\hline Aetiology \\
\hline - age \\
- race \\
- family history \\
- diet \\
\hline
\end{tabular}

Box 1

\begin{tabular}{|l|}
\hline Presentation \\
\hline - symptoms of bladder outlet \\
obstruction (the majority) \\
- incidental finding \\
- metastatic disease \\
- screening \\
\hline
\end{tabular}

Box 2 


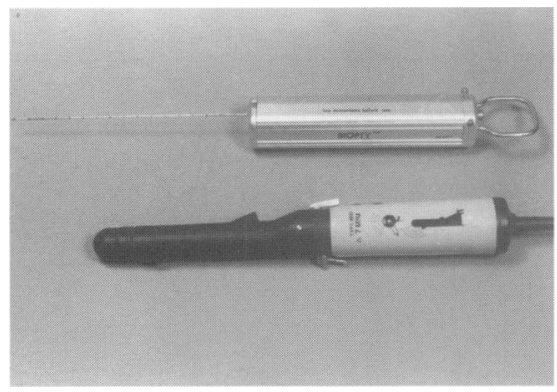

Figure 1 Transrectal ultrasound probe and biopsy gun

\begin{tabular}{|l|}
\hline Prostatic causes of an \\
increased PSA \\
\hline - prostatitis \\
- infarct \\
- benign prostatic hypertrophy \\
- manipulation \\
\hline
\end{tabular}

Box 3

\begin{tabular}{|l|}
\hline PSA parameters used to aid \\
diagnosis of prostate cancer \\
\hline range \\
- age specific \\
- density \\
- velocity \\
\hline
\end{tabular}

Box 4

\begin{tabular}{|l|}
\hline Investigations needed to \\
stage prostate cancer \\
\hline - transrectal ultrasound \\
- MRI \\
- bone scan \\
chest X-ray \\
\hline
\end{tabular}

Box 5 correlates well with the positive predictive value of digital rectal examination. On biopsy samples from clinically normal prostates a positive predictive value of $2 \%$ was calculated, compared to $83 \%$ on those with marked induration. ${ }^{2}$

Transrectal ultrasound (figure 1) is the commonest modality used to image the prostate. It is of limited benefit with a distinctly palpable lesion. However, when the rectal examination is unremarkable and the PSA is raised, the positive predictive value of a transrectal ultrasound-guided biopsy is $16.4 \%$. If the PSA is normal and the rectal examination abnormal it is $13 \%$, and if both tests are unremarkable it falls to $9.3 \% .^{3}$ If digital rectal examination is abnormal and a digitally guided biopsy result is benign then in the same cohort a transrectal ultrasound-guided biopsy will be positive in $53 \%$ of patients. ${ }^{4}$ The addition of sextant biopsies further improves the detection rate. ${ }^{5}$

PSA is the best marker for prostatic carcinoma and probably the best tumour marker currently available. It is an established immunohistochemical marker and is used to monitor patients. It can also be used to aid staging and diagnosis, and proponents of screening strongly advocate its use as a screening tool. PSA is secreted into the ductal system of the prostate where it catalyses the liquefaction of the seminal coagulum after ejaculation. Any process which disrupts the normal architecture of the prostate allows diffusion of PSA into the stroma, here it gains access to the blood stream via the stromal microvasculature. Elevated levels of serum PSA are detected in prostatitis, infarcts, benign prostatic hypertrophy, transiently after prostatic manipulation and with prostatic adenocarcinoma. Cancer produces less PSA per cell than benign epithelium but the greater number of malignant cells and the stromal disruption associated with cancer account for the clinically important elevation in serum PSA levels. ${ }^{6}$

A number of PSA parameters have been described to improve its sensitivity, specificity, and clinical utility. The normal range of PSA is less than $4.0 \mathrm{ng} / \mathrm{ml}$, however in $20 \%$ of patients with newly diagnosed prostatic carcinoma, PSA levels are less than $4.0 \mathrm{ng} / \mathrm{ml}$. PSA may increase with age as a result of benign hypertrophy. Therefore, age-specific reference ranges (table 1) have been introduced and appear to increase the sensitivity of PSA in men under 60 years old and the specificity in men over 60 years. $^{7}$

PSA density (ie, serum PSA divided by the volume of the prostate) was introduced to adjust for contribution of benign prostatic hypertrophy to serum PSA levels. Some authors have found it to be a better predictor of pathological stage than the Gleason grade, ${ }^{8,9}$ but others have not found this parameter useful. ${ }^{7,10}$ A PSA velocity, ie, the rate of increase of PSA over time, greater than $0.75 \mathrm{ng} / \mathrm{ml}$ per year is an accurate predictor of cancer identifying $72 \%$ of cancer cases with a specificity of $90 \%{ }^{11}$ In cohort studies serum PSA correlates with cancer volume, tumour grade and pathological stage, ${ }^{12,13}$ but it is not reliable on an individual basis.

If PSA is used as the initial test in asymptomatic men more than 50 years of age, then with the aid of transrectal ultrasound-guided biopsies $22 \%$ of men with a PSA of $4.0-9.9 \mathrm{ng} / \mathrm{ml}$ are diagnosed as having carcinoma of the prostate. This figure increases to $67 \%$ in men with PSA $>10.0 \mathrm{ng} / \mathrm{ml} .{ }^{14}$

Any of the three primary investigations can lead to a tissue biopsy, but PSA is the most sensitive single parameter ${ }^{14}$ and the positive predictive value of rectal examination and transrectal ultrasound can be increased with a raised PSA. Once the diagnosis of prostatic carcinoma is made, staging is carried out with radiological imaging, a nuclear bone scan and transrectal ultrasound. As part of the World Health Organisation consensus conference on imaging it was concluded that magnetic resonance imaging (MRI; figure 2) is superior to other modalities in the assessment of local tumour stage, particularly if an endorectal coil was used. ${ }^{15,16}$ The majority of lesions arise in the peripheral zone and are seen as low signals on T2-weighted images. The accuracy of MRI in differentiating invasive from localised disease is well established. A peripheral zone defect of $1 \mathrm{~cm}$ or more with an ill-defined border and of low signal proved to be $100 \%$ sensitive ${ }^{17}$ and $54 \%$ specific $^{18}$ for extracapsular spread. The value of MRI in detecting nodal disease is limited to an evaluation of lymph node size and its accuracy, ie, $80-90 \%$, has not exceeded that of computed tomography (CT) ${ }^{19}$ Any node greater than $1.5 \mathrm{~cm}$ is likely to be malignant.

Table 1 Age-specific reference ranges for PSA

\begin{tabular}{llllllllll}
\hline Age (years) & 40 & 45 & 50 & 55 & 60 & 65 & 70 & 75 & 80 \\
PSA (ng/ml) & 2.0 & 2.4 & 2.8 & 3.3 & 3.8 & 4.5 & 5.3 & 6.2 & 7.2 \\
\hline
\end{tabular}




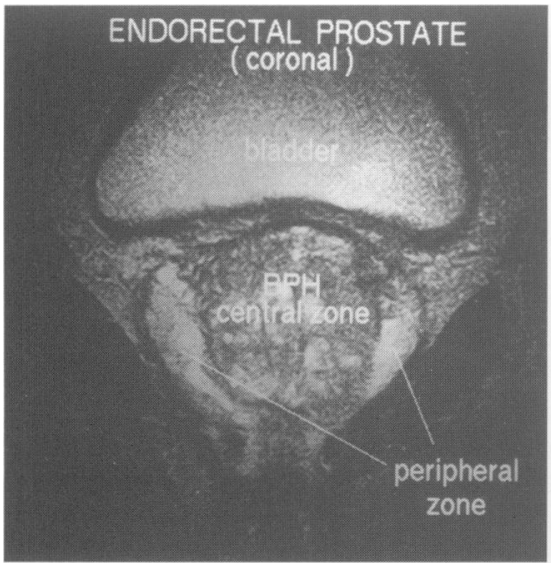

A

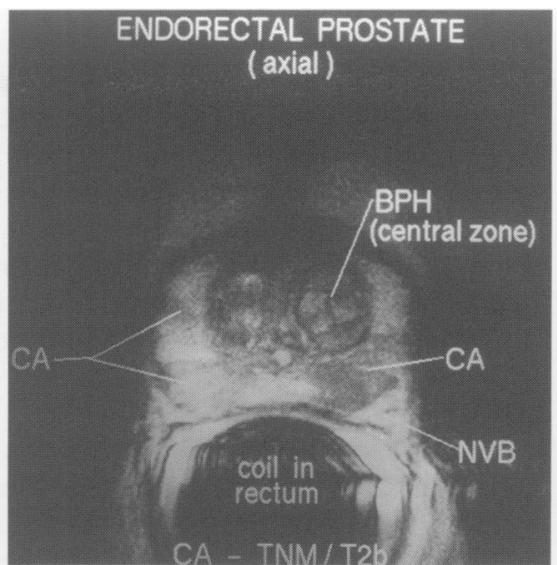

B

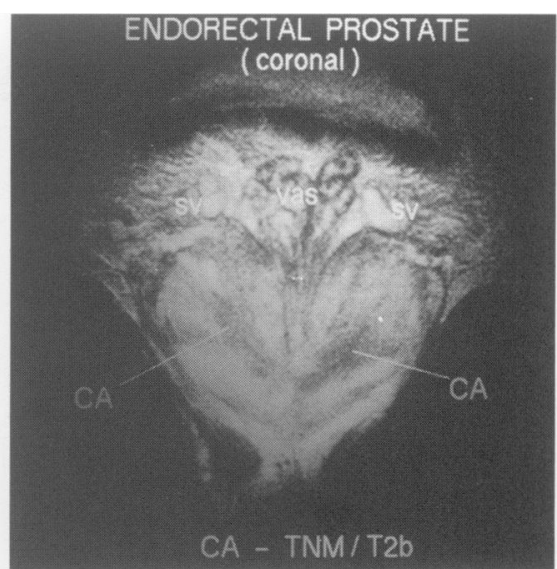

C

Figure 2 Endorectal MRI. (A) coronal view demonstrating normal anatomy; (B) axial view of a prostate with a T2b carcinoma; (C) coronal view demonstrating the vas deferens (vas), the seminal vesicles (sv) and a T2b carcinoma (endorectal images courtesy of J Thompson, Medrad Inc, 1 Medrad Drive, Indianola, USA)

\begin{tabular}{|ll|}
\hline Staging of localised prostate \\
cancer
\end{tabular}

Box 6
Ultrasound imaging of the prostate via the abdominal approach is unreliable, the use of the transrectal probe has allowed excellent high-resolution images of the peripheral zone where $70 \%$ of the carcinomas arise,$^{20}$ however it should be remembered that $24 \%$ of prostatic tumours are iso-echoic. ${ }^{21}$ Transrectal ultrasound detection of local extension is operator dependent and the accuracy varies from 60 to $100 \% .^{22,23}$

The utility of CT is diminishing. It may have a use in situations where MRI scans are inconclusive, eg, in the assessment of para-aortic nodes.

The axial skeleton is the commonest site of haematogenous metastasis (figure 3). Bone metastases are assessed with scintigraphy which can point to the need for plain radiographs. Routine radiographic surveys have no place in imaging for skeletal involvement; they are costly, time-consuming and involve a significant dose of radiation. Furthermore, there must be a $50 \%$ loss of bone density before a lesion is visible ${ }^{24}$ and $23 \%$ of patients judged to be free of bone metastasises by radiography have metastatic disease by scintigraphy. ${ }^{25}$

The mainstay of assessing chest involvement is a chest X-ray. ${ }^{16}$ Serum PSA is determined by prostate cancer volume and by the percentage of high-grade cancer. ${ }^{26}$ Therefore, the use of serum PSA coupled to tumour grade has been advocated as a staging tool. In a series of pelvic lymphadenectomies, if the PSA $<6 \mathrm{ng} / \mathrm{ml}$ and the Gleason score $<5$ all the pelvic lymph nodes were tumour free $(n=142)$, but if the PSA $<10 \mathrm{ng} / \mathrm{ml}$ and the Gleason score $<6$ then $1 \%$ of the pelvic lymph adenectomies were positive $(n=388) .{ }^{27}$

Once the localised tumour has been staged using the TMN classification (box 6), the patient is a candidate for one of the three management regimes available, watchful waiting, radiotherapy, or radical prostatectomy. The course of stage T1a tumours of the prostate is so indolent that an expectant policy is advocated for this tumour. ${ }^{28}$

\section{WATCHFUL WAITING}

Patients are initially followed without treatment and receive subsequent treatment for symptoms eg, androgen ablation for metastatic disease or transurethral resection for outlet obstruction. Limited data are available from four studies about the outcome of watchful waiting (table 2). These studies demonstrate that $31-84 \%$ of patients will progress within five years and that metastases will occur in $9-37 \%$ of patients. Additionally the interim results of the Medical Research Council immediate versus deferred treatment study for carcinoma of the prostate have demonstrated more rapid progression and death in the deferred treatment group for all stages. ${ }^{33}$

Table 2 Localised prostate cancer, deferred therapy: progression, metastatic rate, and prostate cancer death at five years

\begin{tabular}{llllll}
\hline Reference & $\begin{array}{l}\text { Patients } \\
(n)\end{array}$ & $\begin{array}{l}\text { Mean age } \\
\text { (years) }\end{array}$ & $\begin{array}{l}\text { Progression } \\
(\%)\end{array}$ & $\begin{array}{l}\text { Metastatic } \\
\text { rate (\%) }\end{array}$ & $\begin{array}{l}\text { Death } \\
(\%)\end{array}$ \\
\hline 29 & 120 & 75 & 84 & 11 & 20 \\
30 & 223 & 72 & 31 & 9 & 8 \\
31 & 75 & 67 & 69 & 37 & 0 \\
32 & 122 & 68 & 55 & 14 & 1 \\
\hline
\end{tabular}




\begin{tabular}{|l|}
\hline Histological indicators of \\
poor prognosis \\
\hline - high Gleason score \\
- increased expression of proto- \\
oncogenes p53, and $\mathrm{Bcl}_{2}$ \\
- decreased E-cadherin \\
- increased neuroendocrine cells \\
- extra capsular spread \\
\hline
\end{tabular}

Box 7

\section{RADIOTHERAPY}

The Stanford series consists of 1119 patients (from October 1956 to December 1990) treated with external beam irradiation derived from a mid- to high-energy linear accelerator (range, $6-25 \mathrm{mV}$ ); 673 patients had disease limited to the prostate. ${ }^{34}$ These authors found survival to be inversely proportional to clinical stage and pathological grade. At 15 years the survival rates for the best prognosis tumours were equivalent to that of an age-matched cohort, ie, $50 \%$ at 15 years, however, the poorer prognosis tumours had a survival rate of $18 \%$ at 15 years. Age had no influence on outcome.

\section{RADICAL TOTAL PROSTATECTOMY}

Surgery is curative only if all the tumour is removed. Two approaches are advocated, retropubic or perineal; the results are comparable. Precise control of bleeding from the dorsal vein complex allows anatomic dissection of the apex, and thus identifies the branches of the pelvic plexus which innervate the corpora and so preserves sexual function. ${ }^{35}$ Incontinence $(6-10 \%)$ and impotence $(30 \%)$ are serious side-effects.

Data from the Virginia Mason Clinic for patients with localised disease revealed a 15 -year crude survival of $64 \%$ and after 10 years the disease-specific mortality was $2 \%$ with the cause-specific survival curve plateauing at 17 years with no further disease-specific mortality. ${ }^{36}$ The group from Duke University, Durham, NC, demonstrated a significant difference in the failure and death rates between patients with organ-confined, specimen-confined, and marginpositive disease, ie, failure rates of $12 \%, 30 \%, 60 \%$, and death rates of $8 \%$, $12 \%$, and $30 \%$, respectively, at 10 years. ${ }^{37} \mathrm{~A}$ more recent series has shown that the grade of the tumour also affects the rate of progression. ${ }^{38}$ Therefore, cancer control after surgery is affected by tumour grade, and whether the tumour was organ-confined, specimen-confined, or not confined to the specimen. ${ }^{38}$ PSA can also be a measure of recurrence, although biochemical PSA failure may not manifest itself as clinical progression in the patient. ${ }^{38}$

Advocates of screening in Britain suggest there may be a potential benefit in terms of survival if screening is adopted, ${ }^{39}$ although there is considerable disagreement about this. In the USA, early detection programmes detect organconfined disease in a younger cohort of patients. ${ }^{40}$ Long-term follow-up is required to determine if there is an improvement in survival.

The Prostate Cancer Clinical Guidelines Panel has recently published its report on the management of clinically localised prostate cancer. ${ }^{41}$ The report concluded that the then-published data were inadequate for a valid comparison of the treatment options and recommended that all patients with newly diagnosed, clinically localised cancer should be informed of all the treatment options. The appropriate patient for total prostatectomy should have organconfined disease, an expected longevity longer than the natural history of the
Figure 3 (A) Bone scan showing anterior and posterior views and $(B)$ the same patient one year later with progression despite androgen ablation. The PSA has risen by more than $3000 \mu \mathrm{g} / \mathrm{l}$
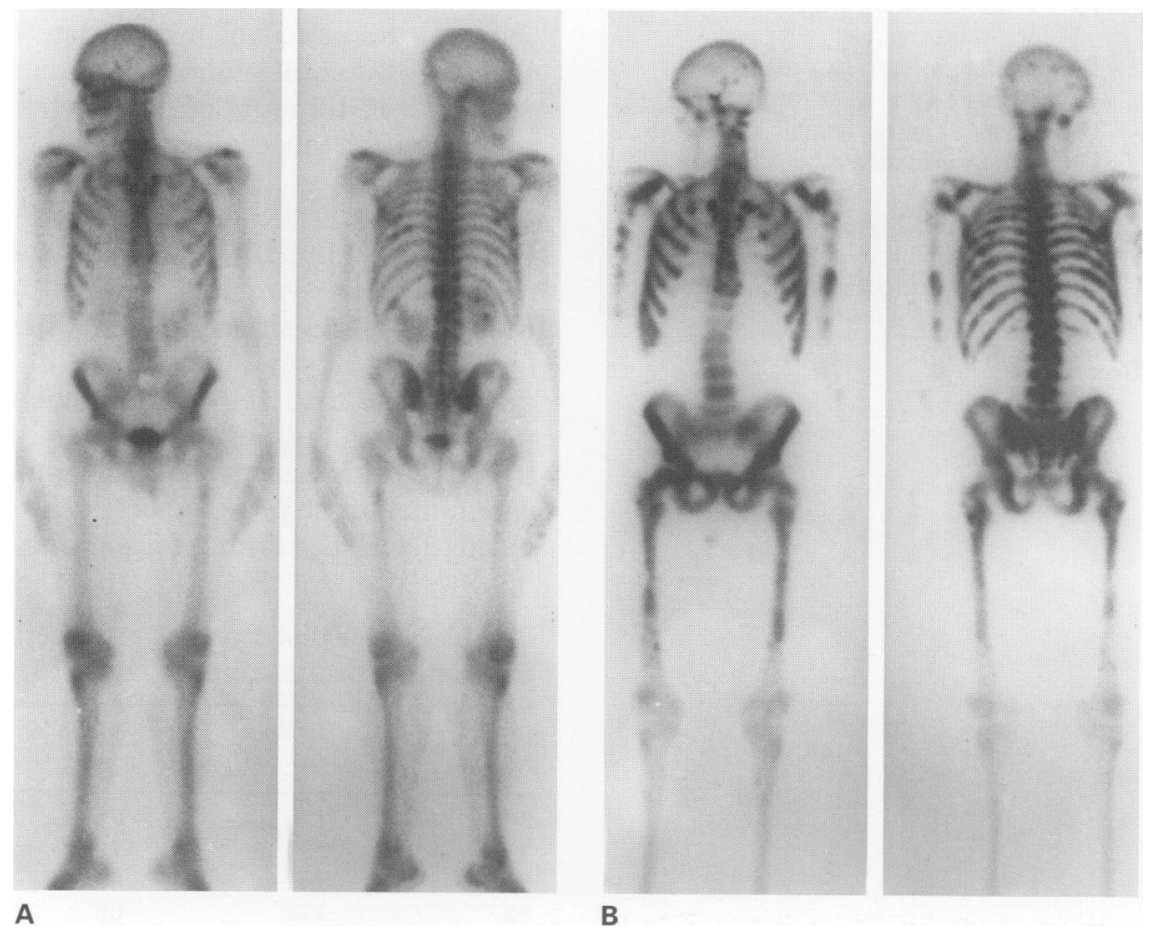

B 
cancer (ie, 15 years), no significant surgical risk factors, and a preference for surgery. The major advantage is the potential for removal of the cancer. The downside includes genitourinary dysfunction and disease progression. The patients most likely to benefit from radiation therapy would have a relatively long life expectancy, no significant risk factors for radiation toxicity, and a preference for radiation therapy. In favour of radiotherapy is the fact it is well tolerated and a potential for cure exists. The adverse effects include radiation cystitis, proctitis, and erectile dysfunction. The prostate is still in place and so disease progression may occur. Patients with a short life expectancy and/or a low-grade tumour are likely to be suitable for surveillance. Disease progression is likely with only a marginal compromise to disease-specific survival at 5 and 10 years. ${ }^{41}$

The absence of hard data is a constant source of embarrassment to all health professionals involved in the management of localised carcinoma of the prostate. The Department of Veterans Affairs and the National Cancer Institute's Cancer Therapy Evaluation Programme Cooperative Study (The Prostate Cancer Intervention Versus Observation Trial (PIVOT)), is a randomised trial designed to determine the benefits of early intervention with radical prostatectomy compared to surveillance. PIVOT will enrol 2000 patients over a three-year period and follow-up will be for a minimum of 12 years. Radiotherapy has not been included as a third treatment arm because of sample size, cost, and feasibility. This study should hopefully answer some of the questions.

The peculiar biology of this disease has contributed to the lack of a consensus about the management of localised prostate cancer. The median age at detection of this disease is 72 years and the median age of death due to prostate cancer is 77 years; since the average life expectancy is 74.2 years, it is evident that the most men will die in spite of the disease rather than because of it. Research is underway to detect markers of aggressiveness. Genetic aberrations have been associated with advanced prostate cancer and these should lead to accurate genetic characterisation of poor prognosis tumours. When coupled with immunohistochemical markers (eg, E-cadherin, p-53), markers for nuclear morphometry, increased angiogenesis, neuroendocrine differentiation, and Gleason score, it should be possible to identify patients at high risk who would benefit from aggressive intervention. ${ }^{42}$

We are entering the dawn of a new era in the management of this disease. It is the authors' belief that high quality research will be needed to aid in our understanding of the biology of this disease and only through better understanding will our management improve.

1 Scardino PT, Weaver R, Hudson MA. Early detection of prostate cancer. Hum Pathol 1992; 23: $211-22$

2 Spring WB, Alden MW. Evaluation of needle biopsy in the diagnosis of prostatic carcinoma. Can Med Assoc F 1954; 70: 179-85.

3 Cooner WH, Mosley BR, Rutherford CL Jr, et Cooner WH, Mosley BR, Rutherford CL Jr, urological practice by ultrasonography, digital urological practice by ultrasonography, digital rectal examination and prostat

4 Hodge KK, McNeal JE, Stamey TA. Ultrasound guided transrectal core biopsies of the palpably abnormal prostate. $\mathcal{F}$ Urol 1989; 142 $66-70$.

5 Hodge KK, McNeal JE, Terris MK, Stamey TA. Random systematic versus directed ultrasound guided transrectal core biopsies of the prostate. ₹ Urol 1989; 142: 71-5.

6 Blackwell KL, Bostwick DG, Myers RP, Zincke $\mathrm{H}$, Oesterling JE. Combining prostate specific antigen with cancer and gland volume to more antigen with cancer and gland volume to more reliably predict pathological stage: the influence
of PSA-cancer density. $¥$ Urol 1994; 151: $1565-$ of $\mathrm{PSA}$

7 Oesterling JE, Cooner WH, Jacobsen SJ, Guess $\mathrm{HA}$, Lieber MM. Influence of patient age on the serum PSA concentration. An important clinical observation. Urol Clin N Am 1993; 20: 607-20.

8 Benson MC, Whang IS, Pantuck A, et al. Prostate specific antigen density: a means of distinguishing benign prostatic hypertrophy and distinguishing benign prostatic hypertrophy

9 Seaman EK, Whang IS, Cooner W, et al. Predictive value of prostate specific antigen density for the presence of micrometastic carcinoma of the prostate. Urology 1994; 43: carcinom 8 .

10 Brawer MK, Aramburu EAG, Chen GL, et al. The inability of prostate specific antigen index to The inability of prostate specific antigen index to
enhance the predictive value of prostate specific enhance the predictive value of prostate specific
antigen in the diagnosis of prostate cancer. $\mathscr{J}$ Urol 1993; 150: 369-73.
11 Carter HB, Pearson JD, Metter JE, et al. Longitudal evaluation of prostate specific antigen in men with and without prostate disease. $\dddot{F} A M A$ 1992; 267: 2215-20.

12 Partin AW, Carter HB, Chan DW, et al. Prostate specific antigen in the staging of localised prostate cancer: influence of tumour differentiation, tumour volume and benign hyperplasia. F Urol 1990; 143: 747-52.

13 Byperplasia. F Urol 1990; 143: 747-52. 3 Blackwell KL, Bostwick DG, Myers RP, Zinke $\mathrm{H}$. Combining prostate specific antigen with
cancer and gland volume to more reliably predict pathological stage: the influence of PSA-cancer density. f Urol 1994; 151: 1565 70.

14 Catalona WJ, Smith DS, Ratliff TL, et al. Measurement of prostate specific antigen in serum as a screening test for prostate cancer. $N$ Engl ₹ Med 1991; 324: 1156-61.

15 Hoisaeter PA, Norlen BJ, Norming U, et al. Imaging in the diagnosis and assessment of prognosis in localised prostate cancer. Consenprognosis in localised prostate cancer. Consen-
sus conference on diagnosis and prognostic sus conference on diagnosis and prognostic
parameters in localised prostate cancer, Stockparameters in localised prostate cancer, Stock-
holm, Sweden, May 12/13, 1993. Scand $f$ Urol holm, Sweden, May 12/13, 1993. Scar
Nephrol 1994; 162(suppl): 89-106.

16 McCarthy P, Pollack HM. Imaging of patients with Stage D prostatic carcinoma. Urol Clin N Am 1991; 18: 35-53.

17 Phillips ME, Kressel HY, Spritzer CE, et al. Prostatic disorders: MR imaging at 1.5T. Radiology 1987; 164: 386-92.

18 Platt JF, Bree RL, Schwab RE. Accuracy of CT in the staging of carcinoma of the prostate. $A \mathcal{F R}$ 1987; 149: $315-8$

19 Bezzi M, Kressel HY, Allen KS, et al. Prostatic carcinoma: MR imaging at 1.5T. Radiology 1988; 169: $339-46$

20 McClennan BL. Transrectal ultrasound of the prostate. Is the technology leading the science. Radiology 1988; 168: $571-5$.
21 Danhert WF, Hamper UM, Walsh PC, et al. The echogenic focus in prostatic sonograms with xeroradiographic and histopathologic correlation. Radiology 1986; 159: 95-100.

22 Rifkin MD, Danhert W, Kurtz AB. State of the art: endorectal sonography of the prostate gland. aft: endorectal sonography

23 Scardino PT, Shinohara K, Wheller TM, et al. Staging of prostate carcinoma: value of ultrasonography. Urol Clin North Am 1989; 16: 713 24 .

24 Lentle BC, Mcgown DG, Dierich H. Technetium- $99 \mathrm{~m}$ polyphosphate bone scanning in carcinoma of the prostate. $\operatorname{Br} \mathcal{F}$ Urol 1974; 128: 543-8.

25 Paulson DF. The impact of current staging procedures in assessing the disease extent of prostatic adenocarcinoma. F Urol 1979; 121: prostatic

26 Kabalin JN, McNeal JE, Johnstone IM, Stamey TA. Serum prostate specific antigen and the biologic progression of prostate cancer. Urology 1995; 46: $65-70$.

27 Naryan P, Fournier G, Gajendran V, et al. Utility of preoperative serum PSA concentration and biopsy Gleason score in predicting risk of pelvic lymph node metastases in prostate cancer. Urology 1994; 44: 519-24.

28 Gibbons RP. Localised prostate carcinoma. Cancer 1993; 72: 2865-72.

29 George NJR. Natural history of localised of prostate cancer managed by conservative therapy alone. Lancet 1988; 1: 494-7.

30 Johansson JE, Adami HO, Andersson SO, Bergstrom R, Krusemo UB, Kraaz W. Natural history of localised of prostate cancer: a populahistory of localised of prostate cancer: a popula-
tion based study in 223 untreated patients. tion based study in 223
Lancet 1989; 1: $799-803$.

31 Whitmore WF Jr, Warner JA, Thompson IM Expectant management of localised prostatic carcinoma. Cancer 1991; 67: 1091-6. 
32 Adolfsson J, Carstensen J, Lowhagen T. Deferred treatment in clinically localised prostatic cancer. $B r f$ Urol 1992; 169: 183-7.

33 Kirk D, for the MRC Prostate Cancer Working Party and Investigators. Hormone therapy in advanced prostate cancer - report of the Medical Research Council 'immediate' versus 'deferred' treatment study. Br f Urol 1996; 77(suppl 1): 204,52 .

34 Bagshaw, MA, Kaplan ID, Cox RC. Radiation therapy for localised disease. Cancer 1993; 71: $939-52$.

35 Walsh PC. Radical retropubic prostatectomy: an anatomic approach. In: Walsh PC, Retik AB Stamey TA, Vaughn ED Jr, eds, Campbell's Urology, 6th edn. Philadelphia: WB Saunders, 1992; pp 2865-86.
36 Gibbons RP, Correa RJ Jr, Brannen GE, Weissman RM. Total prostatectomy for localised prostate cancer: long term results. $f$ Urol 1989 ; 141: $564-6$.

37 Paulson DF, Moul JW, Walther PJ. Radical prostatectomy for clinical stage T1-2N0M0 prostatic adenocarcinoma: long term results. $f$ Urol 1990; 144: 1180-4

38 Epstein JI, Carmichael MJ, Pizov G, Walsh PC. Influence of capsular penetration on progression following radical prostatectomy: a study of 196 cases with long-term follow-up. F Urol 1993; 150: $135-41$.
39 Parkes C, Wald NJ, Murphy P, George L, Watt HC, Kirby R. Prospective obsevational study to assess value of prostate specific antigen as screening for prostate cancer. $B M \mathcal{F}$ 1995; 311: $340-3$.

40 Andriole GL, Catalona WJ. Using PSA to screen for prostate cancer. Urol Clin N Am 1993; 20: for prostate

41 Middleton RG, Thompson IM, Austenfeld MS, et al. Prostate cancer clinical guidelines panel summary report on the management of clinically localised prostate cancer. F Urol 1995; 154: $2144-8$

42 Waxman J, Sheer D. Is prostate cancer worth diagnosing? Lancet 1995; 346: 1177-8. 